\title{
Verbos de movimento e preposições direcionais ${ }^{1}$ \\ António Leal, Fátima Oliveira e Purificação Silvano \\ FLUP/CLUP
}

\begin{abstract}
:
The main objective of this paper is to study the semantics of verbs of inherently directed motion (Levin, 1993) ir ('go') and vir ('come') combined with prepositional phrases with the thematic role of Goal, headed by the prepositions para ('to) and até ('to') in European Portuguese. The data from our news-based-corpus reveals that both prepositions can occur with motion verbs without any apparent restrictions and introduce complements of the verbs $i r$ and vir, although they carry slightly different interpretations: with para, there is a reading that the entity that undergoes movement remains longer in destination than with até. When these prepositions occur within predications that describe non-physical movement, the restrictions increase. The contribution of these prepositions to the determination of the aspectual profile of predications that represent events of movement, namely telicity, poses some theoretical problems, which will also be addressed. This paper puts forward some hypotheses of explanation of the data to be developed in future work.
\end{abstract}

Keywords: Verbs of movement, prepositions, Aspect; telicity.

Palavras-chave: Verbos de movimento; preposições; Aspeto, telicidade.

\section{Introdução}

Os verbos de movimento ir e vir podem ocorrer num número bastante alargado de contextos, sendo suscetíveis de serem classificados de forma diversa e dando origem a um leque de interpretações variado. Enquanto verbos principais, os predicados que projetam podem denotar eventualidades que cabem numa classificação bipartida: ou são denotados eventos de movimento físico, ou são denotados eventos associados a uma noção de movimento que varia no grau de abstração (ou 'não físico'). A esta divisão baseada no significado podem ser associadas, ou não, restrições relativas às preposições que podem coocorrer com estes verbos, nomeadamente as preposições que introduzem sintagmas preposicionais (SPs) com a função semântica de Alvo ou Destino. Se, nos casos de movimento 'não físico', essas restrições são evidentes, nos casos de movimento físico, aparentemente, há uma maior flexibilidade e várias preposições podem ocorrer nestes contextos, nomeadamente as preposições a, para e até. Contudo, as interpretações não são as mesmas, variando de forma uniforme consoante a preposição. Para além disso, do ponto de vista aspetual, os testes aplicados às predicações dão origem a resultados aparentemente contraditórios.

\footnotetext{
${ }^{1}$ Este trabalho é financiado pela Fundação Calouste Gulbenkian (apoio a projetos de investigação nos domínios da língua e da cultura portuguesas), ref. 139614.
} 
Este artigo constitui-se, assim, como um primeiro passo na análise das propriedades aspetuais das predicações que combinam os verbos ir e vir com sintagmas preposicionais. São dois os objetivos principais: por um lado, descrever as diversas interpretações que podem ser atribuídas aos verbos de movimento ir e vir quando combinados com SPs encabeçados pelas preposições para e até (restringimo-nos aos eventos de movimento) e, por outro lado, elencar algumas peculiaridades de natureza aspetual deste tipo de construções. Deste modo, na secção 1, apresentamos uma caracterização geral das possibilidades combinatórias dos verbos ir e vir com SPs com para e até. Esta caracterização baseia-se essencialmente num corpus constituído a partir de notícias do jornal on-line Observador. Na secção 2, são traçados os perfis aspetuais das predicações em análise, através da aplicação de um conjunto de testes. Terminamos com o levantamento de algumas hipóteses de explicação dos dados.

\section{Descrição geral das combinações dos verbos com preposições}

Esta secção é dedicada à descrição das possibilidades combinatórias dos verbos $\mathrm{ir} /$ vir com as preposições para e até que foram identificadas no corpus, tendo este sido constituído, tal como referido na introdução, com frases extraídas do jornal on-line Observador durante o mês de janeiro de 2016. Neste artigo, os exemplos extraídos do corpus estão assinalados.

\subsection{Verbo ir}

Principiaremos a nossa descrição pelos dados relativos ao verbo $i r$. Em primeiro lugar, apenas a preposição para pode ocorrer incluída em expressões lexicalizadas, como em (1); não foram encontrados casos de expressões lexicalizadas com a preposição até.

(1) As "fortes tempestades" que sopram no Dakar cancelam a primeira etapa, embora deixem que a segunda vá para a estrada. (corpus)

Em segundo lugar, ambas as preposições, para e até, podem ocorrer em contextos em que não são substituíveis pela outra preposição. Associado a esta impossibilidade de substituição, 
verificou-se que, em todos estes casos, as predicações não eram interpretadas como eventos de movimento. Vejam-se os exemplos $(2)^{2}$.

(2a) Qualquer casal não-heterossexual que troque afetos em público poderá ter de pagar uma coima entre 48 e $60 €$ e, caso aconteçam em instituições culturais ou educativas, a pena pode ir até 15 dias de prisão. (corpus)

Cf. * ir para 15 dias de prisão

(2b) José Sá pediu que o agente estivesse presente no momento de concretizarmos as condições, já que tinha acordo para ir para outro clube. (corpus)

$$
\text { Cf. * ir até outro clube }
$$

Contudo, as preposições para e até podem ocorrer em contextos em que se podem substituir. Neste caso, a permuta de uma preposição por outra acarreta alterações de significado. Associado a esta possibilidade de substituição, verifica-se que os predicados têm a interpretação de eventos de movimento. Veja-se o exemplo (3).

(3) agora posso encostar-me, relaxar e não ter de pôr o alarme, acordar e ir para o ginásio (corpus)

\section{Cf. \# ir até ao ginásio}

As diferenças de interpretação associadas às preposições em (3) podem ser descritas, de uma maneira informal, da seguinte forma: as predicações com a preposição para parecem ter uma leitura em que a entidade que sofre o movimento permanece mais tempo no Destino do que com até, ou que essa permanência não tem implícito um término (o que acontece com até). Por esse motivo, quando o nosso conhecimento do mundo determina que a estadia no Destino é breve ou provisória, apenas ocorre a preposição até, mesmo com eventos de movimento. É o que se passa com os exemplos (4) e (5).

\footnotetext{
${ }^{2}$ Note-se que ambos os exemplos de (2) podem ter uma interpretação como eventos de movimento, caso em que é possível a permuta das preposições.
} 
(4) Antes de ir para Bruxelas e integrar a comissão europeia, primeiro com Barroso e depois com Juncker como vice-presidente para o orçamento e para a ajuda humanitária (corpus)

$$
\text { Cf. * ir até Bruxelas }
$$

(4a) Ela foi \{para/até\} Bruxelas.

(5) No sábado o Benfica recebe o Arouca e o Sporting vai até Paços de Ferreira (corpus) Cf. * ir para Paços de Ferreira

(5a) O João e o Pedro estão ocupados no sábado: o João recebe os pais e o Pedro vai para Paços de Ferreira porque arranjou lá emprego e começa a trabalhar no domingo.

$$
\text { Cf. * ir até Paços de Ferreira }
$$

No primeiro caso, a estadia no Destino (Bruxelas) é entendida como prolongada e sem um término implícito devido ao conteúdo da oração coordenada copulativa "e integrar a comissão europeia", que associa a ida para Bruxelas ao desempenho de um cargo profissional/político. Neste contexto, a substituição de para por até não é possível. Contudo, se não houver nada que force a leitura anterior do SP com para, como em (4a) a substituição desta preposição por até volta a ser possível.

O inverso acontece em (5). Neste caso, a estadia do Sporting (uma equipa de futebol de Lisboa) em Paços de Ferreira é entendida como transitória e com um término implícito, dado que a equipa de futebol se deslocou apenas para disputar uma partida de futebol, finda a qual regressa à sua cidade. Neste contexto, até não pode ser substituída por para, e isso não depende do tipo de complemento: repare-se que, em (5a), o complemento da preposição para é, novamente, "Paços de Ferreira", mas como o contexto criado é semelhante ao de (4), não só para é permitida, como é a única preposição possível.

Para terminar esta descrição geral do verbo $i r$, de referir que este verbo se combina com as preposições para e até numa construção que pode ser confundida com a construção de verbo auxiliar 'ir + infinitivo', na ausência de SP (cf. Raposo, 2013:1263-1265). Veja-se (6). Há, contudo, algumas diferenças a apontar relativamente às preposições. Por um lado, e tal como se viu antes, com para, parece haver leitura em que a entidade permanece mais tempo no Destino do que com até. Por outro lado, os SPs com para aparentam ser mais facilmente deslocáveis do que SPs com até, tal como ilustrado em (6a). 
(6) portanto, íamos para a rua brincar (corpus)

Cf. íamos até à rua brincar

(6a) íamos brincar para a rua / *??? íamos brincar até à rua

\subsection{Verbo vir}

Passemos agora à descrição do corpus no que concerne ao verbo vir. Para começar, não se encontram atestados no corpus casos de expressões lexicalizadas envolvendo as preposições para e até: apenas a preposição $a$ foi encontrada em contextos deste tipo, dos quais (7) é um exemplo.

(7) Entretanto, o socialista João Galamba já veio a terreiro defender a decisão do governo liderado por António Costa. (corpus)

Cf. vir $\{*$ para $/ *$ até\} terreiro

Para além disso, apenas a preposição para pode ocorrer em contextos em que não é substituível por outra preposição. Tal como se verificou com o verbo $i r$, nestes casos não são denotados eventos de movimento (cf. (8)).

(8) esses bens têm que ser leiloados e essa receita tem que vir para o orçamento de estado. (corpus)

Cf. * vir até ao orçamento de estado

Por fim, e tal como com o verbo ir, também com o verbo vir são possíveis as preposições no mesmo contexto, quando é denotado um evento de movimento, como em (9), e com a mesma alteração de significado.

(9) muitas vezes os familiares não podem vir para Portugal e também acontece que se algum deles tem necessidade de sair de Portugal já não pode regressar (corpus)

Cf. vir até Portugal

Em suma, o que se verifica no corpus é que, quando ambas as preposições podem ocorrer com estes verbos, nos mesmos contextos, as predicações são sempre interpretadas como 
eventos de movimento. Por outro lado, embora os SPs introduzidos por estas preposições sejam sempre associados à função de Destino, há diferenças de interpretação. Na secção seguinte, veremos que esta não é a única diferença a apontar às preposições.

\section{Eventos de movimento com verbos ir e vir: algumas questões sintáticas e semânticas}

Nesta secção, procuraremos pôr em destaque algumas semelhanças e diferenças entre os SPs introduzidos por para e até. Principiaremos por breves considerações de natureza sintática. Posteriormente, abordaremos alguns problemas relacionados com leituras aspetuais.

\subsection{Aspetos sintáticos dos SPs com para e até}

O primeiro aspeto a salientar é o facto de os SPs introduzidos por para e até se comportarem, com ambos os verbos, como complementos, como se mostra em (10).

(10a) * O João \{foi/veio $\}$ para casa e a Maria fez o mesmo para a escola. (fazer o mesmo $=\{\mathrm{ir} / \mathrm{vir}\})$

(10b) * O que é que o João fez para casa? \{Foi/veio\}.

(11a) * O João \{foi/veio $\}$ até casa e a Maria fez o mesmo até à escola. (fazer o mesmo $=\mathrm{ir} / \mathrm{vir}$ )

(11b) * O que é que o João fez até casa? \{Foi/veio $\}$.

De notar que, devido à componente deítica do significado dos verbos ir e vir, estes podem ocorrer, em certos contextos, sem o complemento expresso. Como se exemplifica em (12), o verbo vir ocorre mais facilmente neste contexto do que o verbo ir (cf. (12a) e (12b) vs. $(12 \mathrm{c}))$.

(12a) O rapaz $\{*$ foi / veio $\}$.

(12b) Pergunta: $\{*$ Quem foi? / Quem veio?\}. Resposta: O rapaz.

(12c) O rapaz já \{foi / veio $\}$.

Em suma, a distinção de significado associada a estas preposições parece ter motivações lexicais, e não sintáticas. 


\subsection{Aspetos semânticos dos SPs com para e até}

Passemos agora às particularidades semânticas destas construções. Em primeiro lugar, estes verbos não admitem a coocorrência com uma expressão de medição espacial, como é ilustrado em (13). Esta é uma particularidade dos verbos de movimento inerentemente direcionado e foi apontada já na literatura sobre outras línguas (cf., e.g., Levin, 1993, para o Inglês).

(13) * O rapaz \{foi/veio\} \{para casa/até casa\} 30 metros.

Em segundo lugar, a combinação destas construções com o adverbial temporal em $x$ tempo é possível. Este é um teste habitualmente apontado na literatura como diagnóstico de predicações durativas e télicas, ou seja, de Processos Culminados (cf. Moens, 1987). Assim, em (14), o adverbial "em 5 minutos" está a medir toda a extensão temporal dos eventos. Embora não haja qualquer problema com os exemplos (14a) e (14b), com SP com até, é de referir que alguns informantes indicaram os exemplos (14c) e (14d), com SP com para, como casos em que a aceitabilidade não é completa. Note-se que esses mesmos informantes não têm problemas com estas frases sem o adverbial temporal.

(14a) O rapaz foi até à faculdade em $5 \mathrm{~m}$.

(14b) O rapaz veio até à faculdade em $5 \mathrm{~m}$.

(14c) ? O rapaz foi para a faculdade em $5 \mathrm{~m}$.

(14d) ? O rapaz veio para a faculdade em $5 \mathrm{~m}$.

Já os resultados da combinação destas construções com o adverbial temporal durante $x$ tempo são distintos. Comecemos pelos casos com até. Ambos os exemplos (15) são gramaticais, mas em ambos o adverbial não está a medir o evento, ou uma parte do evento, mas um intervalo de tempo após a ocorrência do evento. Por outras palavras, em (15), o adverbial "durante 5 m" não mede o evento "o rapaz ir/vir até à faculdade", ou uma parte desse evento, mas o período de tempo durante o qual o rapaz esteve na faculdade após o evento "o rapaz ir/vir até à faculdade" cessar, ou seja, o adverbial temporal mede o estado consequente do evento.

Os exemplos (16) são ambíguos, na medida em que o adverbial temporal durante $x$ tempo pode estar a medir intervalos diferentes. Por um lado, o adverbial temporal pode medir 
o estado consequente, da mesma forma que foi descrita relativamente aos exemplos (15). Por outro lado, o adverbial temporal pode medir o processo preparatório do evento, ou seja, mede um intervalo de tempo que engloba o início do evento "o rapaz ir/vir para a faculdade", mas não o seu fim. Deste modo, as frases (16) são ambíguas entre uma leitura em que o rapaz chega à faculdade (primeira leitura, de medição do estado consequente) e uma leitura em que o rapaz não chega à faculdade (segunda leitura, de medição do processo preparatório).

(15a) $\mathrm{O}$ rapaz foi até à faculdade durante $5 \mathrm{~m}$. (= esteve na faculdade $5 \mathrm{~m}$.)

(15b) O rapaz veio até à faculdade durante $5 \mathrm{~m}$. (= esteve na faculdade $5 \mathrm{~m}$.)

(16a) O rapaz foi para a faculdade durante $5 \mathrm{~m}$. (= esteve a ir para a faculdade durante $5 \mathrm{~m}$. / esteve na faculdade $5 \mathrm{~m}$.)

(16b) O rapaz veio para a faculdade durante $5 \mathrm{~m}$. (= esteve a ir para a faculdade durante $5 \mathrm{~m}$. / esteve na faculdade $5 \mathrm{~m}$.)

Um outro contexto em que se verifica uma assimetria entre as preposições em análise é o dos sintagmas direcionais. Na verdade, quando o SP tem uma interpretação meramente direcional, apenas para pode ocorrer. Vejam-se (17) e (18). O primeiro elemento de cada par, com para, tem uma interpretação meramente direcional, o que é impossível relativamente ao segundo elemento de cada par; este só é gramatical se os complementos da preposição ("a direita", "oeste") forem interpretados como Destino ou Alvo, ou seja, como ponto final do movimento.

(17) vai tudo para \{a direita / oeste $\}$ * / \# vai tudo até \{à direita / oeste $\}$

(18) vem tudo para \{a direita / oeste $\}$ * / \# vem tudo até \{à direita / oeste $\}$

Esta mesma assimetria relativa à possibilidade de ocorrência das preposições verificase quando se combinam estas construções com o Progressivo. Neste contexto, apenas é possível a combinação com SP com para, pois, com SP construído com até, os resultados são muito pouco aceitáveis numa leitura de evento único. Vejam-se os exemplos (19). Ambos os casos com para ((19a) e (19c)) são gramaticais, sendo descrita uma fase medial de uma mesma eventualidade, pelo que, em ambos os casos, o rapaz não chegou ainda à faculdade no momento da enunciação, ou seja, trata-se de casos do paradoxo do imperfectivo. Já os exemplos com até 
((19b) e (19d)) são pouco aceitáveis ou mesmo agramaticais, numa leitura de evento único, sendo gramaticais apenas se as frases em questão receberem uma leitura de habitualidade, o que é facilitado pela inserção de, por exemplo, um quantificador de frequência (cf. está a \{ir/vir\} até à faculdade todas as manhãs).

(19a) O rapaz está a ir para a faculdade.

(19b) ??? ${ }^{\mathrm{k}} \mathrm{O}$ rapaz está a ir até à faculdade.

(19c) O rapaz está a vir para a faculdade.

(19d) ???/مk $\mathrm{O}$ rapaz está a vir até à faculdade.

Já o comportamento destas construções no escopo de parar de é distinto dos casos anteriores, na medida em que, com ambas as preposições, os resultados são muito pouco aceitáveis ou mesmo agramaticais numa leitura de evento único, como se pode observar em (20). Note-se que, tal como foi referido a propósito dos exemplos (19b) e (19d), todos os exemplos em (20) são gramaticais só se as frases receberem uma leitura de habitualidade (cf. parar de ir para a faculdade todos os dias).

(20a) ???/* O rapaz parou de ir para a faculdade.

(20b) ???/* O rapaz parou de ir até à faculdade.

(20c) ???/* O rapaz parou de vir para a faculdade.

(20d) ???/* O rapaz parou de vir até à faculdade.

Uma outra diferença entre as preposições, relevante do ponto de vista aspetual, prendese com as implicações a que dão origem. Um dos testes apontados na literatura para a identificação de Processos Culminados está relacionado com as implicações desencadeadas pela combinação do Perfeito com adverbiais do tipo em x tempo (cf. Dowty, 1979): a ocorrência de Processos Culminados no Pretérito Perfeito e no escopo de um adverbial do tipo em x tempo implica a verdade da forma progressiva correspondente durante o período de tempo indicado. A combinação dos verbos ir e vir com a preposição para apresenta os resultados esperados, tendo em conta o comportamento destes exemplos no escopo de em $x$ tempo (cf. exemplos (14c) e (14d)), na medida em que as inferências desencadeadas correspondem às inferências próprias dos Processos Culminados, tal como se exemplifica em (21a) e (21b). Contudo, o mesmo não 
se verifica com os exemplos (21c) e (21d), em que comparece a preposição até, o que, aparentemente, constitui um resultado contraditório, relativamente ao que se verificou aquando da compatibilidade com em x tempo (cf. exemplos (14a) e (14b)).

(21a) ? O rapaz foi para a faculdade em $5 \mathrm{~m}$.

$\rightarrow$ O rapaz esteve a ir para a faculdade durante esses $5 \mathrm{~m}$.

(21b) ? O rapaz veio para a faculdade em $5 \mathrm{~m}$.

$\rightarrow$ O rapaz esteve a vir para a faculdade durante esses $5 \mathrm{~m}$.

(21c) $\mathrm{O}$ rapaz foi até à faculdade em $5 \mathrm{~m}$.

† $\mathrm{O}$ rapaz esteve a ir até à faculdade durante esses $5 \mathrm{~m}$.

(21d) $\mathrm{O}$ rapaz veio até à faculdade em $5 \mathrm{~m}$.

$\nrightarrow$ O rapaz esteve a vir até à faculdade durante esses $5 \mathrm{~m}$.

O último aspeto a destacar diz respeito à possibilidade de existência de leituras de "evento incompleto". Nestas leituras, há material linguístico que procede ao cancelamento da culminação existente no núcleo aspetual dos Processos Culminados, pelo que as predicações são interpretadas como denotando eventos que não atingem o seu término intrínseco. O que os exemplos (22) e (23) mostram é que as preposições para e até dão origem a leituras distintas: enquanto para licencia leituras de "evento incompleto" (cf. exemplos (22)), até não as permite (cf. exemplos (23)).

(22a) O rapaz veio para a faculdade, mas, a meio do caminho, teve de voltar para trás.

(22b) O rapaz foi para a faculdade, mas, a meio do caminho, teve de voltar para trás.

(23a) * O rapaz veio até à faculdade, mas, a meio do caminho, teve de voltar para trás.

(23b) * O rapaz foi até à faculdade, mas, a meio do caminho, teve de voltar para trás.

Os dados que foram apresentados nesta secção constituem um puzzle de difícil resolução, na medida em que os resultados da aplicação dos testes dão origem a conclusões aparentemente contraditórias. Se, por um lado, os SPs introduzidos tanto por para como por até aparentam ser complementos dos verbos ir e vir (o que é parcialmente distinto do que se passa com as mesmas preposições quando combinadas com verbos de modo de movimento; cf. Leal \& Oliveira, 2008; 2015), por outro lado, a sua contribuição para a construção aspetual das 
predicações e o próprio perfil aspetual das predicações não são claros. Destacam-se os seguintes aspetos (referidos anteriormente nesta secção).

1. Ambas as preposições se combinam com em x tempo (embora alguns informantes considerem os exemplos com para não totalmente gramaticais), o que identifica as predicações como Processos Culminados.

2. Quando combinadas com durante $x$ tempo, as preposições dão origem a interpretações distintas: para permite tanto uma leitura de medição do processo preparatório do evento, como uma leitura de medição do estado consequente; até apenas permite a leitura de medição do estado consequente. Note-se que apenas a leitura de medição do processo preparatório é própria dos Processos Culminados, enquanto a leitura de medição do estado consequente é uma leitura que se pode encontrar tipicamente em Culminações (eventualidades não durativas e télicas).

3. Apenas para pode ter leitura meramente direcional (em que o Destino, ou Alvo, não é atingido) e apenas para se combina com o Progressivo. De notar que, em Português Europeu, tipicamente, apenas os Estados não Faseáveis e algumas Culminações não admitem a ocorrência com esta construção.

4. Apenas para dá origem a uma implicação própria de Processo Culminado, quando coocorre no Pretérito Perfeito juntamente com um adverbial do tipo em $x$ tempo. A implicação desencadeada por predicações com até é própria de Culminações.

5. Apenas para dá origem a leituras de "evento incompleto"; com até, não parece ser possível a remoção da culminação do núcleo aspetual.

6. Ambas as preposições rejeitam a combinação com parar de, um teste usado para diagnosticar a duratividade das predicações.

Em suma, não é claro se as predicações que combinam os verbos ir e vir com para e até são durativas ou se são não durativas. Para além disso, também não é evidente qual é a informação trazida pelas preposições para a definição do perfil aspetual das predicações. Embora ambas introduzam complementos com a função semântica de Destino, ou Alvo, apresentam também distinções importantes, que podem ser sumariadas da seguinte forma: para tem associada uma leitura de permanência prolongada, ou sem um término implícito, mas permite que a culminação do núcleo aspetual seja facilmente removida; até tem associada uma leitura de permanência breve, ou com um término implícito, mas não permite que a culminação do núcleo aspetual seja removida. 
A solução para os problemas que foram elencados não pode ser facilmente exposta e ultrapassa o âmbito deste trabalho. No entanto, são apresentadas, na secção seguinte, algumas pistas no sentido de encontrar uma forma de explicar o comportamento aparentemente errático das construções em análise.

\section{Hipóteses de explicação dos dados}

Uma proposta para descrever os dados apresentados terá de dar conta das diferentes formas como as preposições para e até determinam a telicidade das predicações em que ocorrem. Se, como se verificou antes, as predicações são télicas, também é verdade que a telicidade associada a para é mais facilmente removida do que a que está associada a até.

Uma hipótese para descrever esta diferente contribuição das preposições poderá passar por alargar a proposta feita em Leal \& Oliveira (2015), referente à combinação dos verbos de modo de movimento com as preposições para e até, e considerar que também os verbos de movimento direcionado ir e vir denotam escalas de percursos, à semelhança do que Rappaport Hovav \& Levin (2010) propõem para o Inglês. Se se assumir uma proposta como, por exemplo, a de Kennedy \& McNally (2005), uma escala divide-se em três parâmetros: (i) uma dimensão de medição (indica o tipo de medição e a forma como os graus são interpretados); (ii) um conjunto de graus, com a especificação da existência de um valor mínimo ou máximo na escala; (iii) uma relação de ordenação, com a explicitação da ordem nos graus na escala.

Dado que as escalas de percursos estão apenas parcialmente lexicalizadas nos verbos de movimento direcionado (cf. Rappaport Hovav \& Levin, 2010), é necessário que o contexto forneça o valor dos elementos em falta (cf. Fleischhauer \& Gameschlag, 2014). Seguindo Leal \& Oliveira (2015), as preposições para e até dão origem a interpretações parcialmente distintas por completarem a informação em falta no verbo com parâmetros distintos da escala. Para apenas determina a relação de ordenação (aproximação a um determinado ponto definido pelo SP com para), pelo que permite que seja retirada a culminação do núcleo aspetual; por seu lado, até opera sobre o parâmetro do conjunto de graus e denota o elemento máximo da escala projetada pelo verbo, pelo que não permite que seja retirada a culminação do núcleo aspetual.

Esta proposta, aparentemente, dá conta da telicidade variável das preposições, embora seja necessário escrutiná-la de forma mais detalhada (o que não cabe neste trabalho). Para além disso, ela deixa outras questões em aberto e que carecem de mais investigação. Destacaremos duas delas. A primeira prende-se com as leituras distintas das preposições (para associa-se a 
permanência prolongada, ou sem um término implícito; até associa-se a permanência breve, ou com um término implícito). Uma proposta baseada apenas na noção de escala, tal como foi formulada anteriormente, não parece dar conta destas diferentes interpretações.

A segunda questão em aberto prende-se com a natureza das escalas projetadas pelos verbos. Se, por um lado, os eventos denotados parecem ser durativos e télicos, há contextos em que os eventos parecem ser não durativos e télicos (de modo particular, com até). Se os eventos são durativos, então os verbos deverão projetar escalas de múltiplos pontos, mas, se os eventos são não durativos, então os verbos projetarão escalas de apenas dois pontos (cf. Beavers, 2008). A forma de explicar esta variedade pode seguir diferentes percursos. Por exemplo, pode-se considerar que os eventos com estes verbos são na base não durativos (escalas de dois pontos) e ganham duração através de operações de shift aspetual; ou, em alternativa, que os eventos com estes verbos são na base durativos (escalas de múltiplos pontos) e perdem duração através de operações de shift aspetual. Outra hipótese é considerar que os eventos com ir e vir e para são na base durativos e os eventos com até são na base não durativos, pelo que os verbos seriam completamente subespecificados. Uma quarta hipótese passa por considerar que os eventos com estes verbos são na base não durativos, correspondendo a escalas de apenas dois elementos. Contudo, é marcada a transição de uma situação durativa para outra situação durativa, pelo que os elementos da escala não correspondem a pontos, mas a intervalos.

\section{Considerações finais}

Ao longo deste trabalho, foi descrito o padrão de combinação dos verbos de movimento inerentemente direcionado ir e vir com duas preposições, para e até, num corpus constituído a partir de notícias de um jornal on-line. Dado que ambas as preposições podem ocorrer, no mesmo contexto (embora com uma ligeira alteração de significado), quando as predicações denotam eventos de movimento, foi feita uma análise, essencialmente semântica, a este tipo de construções.

Os resultados obtidos são aparentemente contraditórios, na medida em que as predicações parecem ser durativas, mas, em certos contextos, comportam-se como não durativas. Para além disso, a telicidade das predicações está dependente da preposição que ocorre, sendo esta característica aspetual mais facilmente removível quando ocorre a preposição para. 
Para dar conta da telicidade variável destas predicações, avançamos a hipótese (no seguimento de Leal \& Oliveira, 2015, para os verbos de modo de movimento) de que os verbos ir e vir têm um significado lexical que pode ser representado como uma escala parcialmente especificada. Os SPs introduzidos por para e até, que se comportam como complementos dos verbos, contribuem assim de forma distinta para a especificação de algum parâmetro da escala projetada pelo verbo: para determina a relação de ordenação, enquanto até opera sobre o parâmetro do conjunto de graus e denota o elemento máximo da escala projetada pelo verbo.

Uma abordagem escalar à semântica destas construções tem a vantagem de as relacionar com construções em que ocorrem verbos de mudança de estado e de tema incremental, as quais também exibem o mesmo tipo de telicidade variável. Contudo, há ainda um conjunto de características das predicações com ir/vir e paralaté que não têm uma explicação satisfatória, o que constituirá objeto de investigação futura.

\section{Referências}

Beavers, J. (2008) Scalar complexity and the structure of events. In Dölling, J, Heyde-Zybatow, T. \& Schäfer, M. (eds.), Event Structures in Linguistic Form and Interpretation. Berlin: de Gruyter, 245-265.

Dowty, D. (1979) Word Meaning and Montague Grammar. Dordrecht: Reidel.

Fleischhauer, J. \& Gameschlag, T. (2014) We're going through changes: How change of state verbs and arguments combine in scale composition. Lingua 141, pp.30-47.

Hay, J., Kennedy, C. \& Levin, B. (1999) Scalar structure underlies telicity in 'degree achievements'. In Matthews T. \& Strolovitch, D. (eds.) Proceedings of SALT IX. Ithaca: CLC Publications, pp.127-144.

Kennedy, C \& McNally, L. (2005) Scale structure, degree modification, and the semantics of gradable predicates. Language 81 (2), pp.345-381.

Kennedy, C. \& Levin, B. (2008) Measure of change: The adjectival core of degree achievements. In L. McNally \& C. Kennedy (eds.) Adjectives and Adverbs: Syntax, Semantics and Discourse. Oxford: Oxford University Press, pp.156-182.

Leal, A. \& Oliveira, F. (2008) Subtipos de verbos de movimento e classes aspectuais. In Lobo, M. \& M. Antónia Coutinho (eds.) Textos Seleccionados do XXIII Encontro da Associação Portuguesa de Linguística. Lisboa: APL, pp.287-298. 
Leal, A., \& Oliveira, F. (2015) Verbos de movimento, preposições direcionais e escalas. In Revista da Associação Portuguesa de Linguística 1, pp. 353-366.

Levin, B. (1993) English Verb Classes and Alternations: a Preliminary Investigation. Chicago: The University of Chicago Press.

Moens, M. (1987) Tense, Aspect and Temporal Reference. Tese de doutoramento, Universidade de Edimburgo.

Paiva Raposo, E (2013) Verbos auxiliares. In Paiva Raposo, E. et al. (orgs.) Gramática do Português, Lisboa: Fundação Calouste Gulbenkian, pp.1221-1284.

Rappaport Hovav, M. \& Levin, B. (2010) Reflections on manner/result complementarity. In M. Rappaport Hovav, E. Doron, e I. Sichel (eds.) Syntax, Lexical Semantics, and Event Structure. Oxford: Oxford University Press, pp.21-38. 